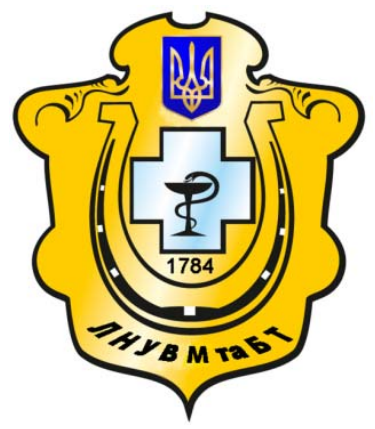

Науковий вісник Львівського національного університету ветеринарної медицини та біотехнологій імені С.З. Гжицького

Scientific Messenger of Lviv National University of Veterinary Medicine and Biotechnologies named after S.Z. Gzhytskyj

doi:10.15421/nvlvet6649

ISSN 2413-5550 print

ISSN 2518-1327 online

$\underline{\text { http://nvlvet.com.ua/ }}$

\title{
The advantages of using the Tono-Pen Vet tonometer in the measurement of IOP in veterinary practice
}

\author{
Karolina Wrześniewska, Dagmara Winiarczyk, Jacek Madany \\ wrzesniewska@gmail.com
}

\begin{abstract}
Sub-Department of Companion Animal Internal Medicine, Department and Clinic of Animal Internal Diseases University of Life Sciences in Lublin, 30 Gtęboka Street, 20-612 Lublin, Poland
\end{abstract}

\begin{abstract}
Objective The aim of this study was to evaluate and to validate the accuracy of the Tono-Pen Vet applanation tonometer in the measurement of IOP in dogs and to observe the advantages and disadvantages of using the Tono-Pen Vet tonometer in clinical practice.

Animals Both eyes of 41 conscious and healthy dogs were evaluated.

Procedure Readings of IOP were taken using tonometry (measured with a Tono-Pen Vet applanation tonometer). The IOP measurement with Tono-Pen Vet tonometer in conscious dogs was accomplished by instillation of 0,5\% Alcaine eye drops.

Results The mean IOP readings with the Tono-Pen Vet were 18,5 $\pm 3,7 \mathrm{mmHg}$ (range 11,5-24,5 $\mathrm{mmHg}$ ).

The correlation coefficient $\left(r^{2}\right)$ between both eyes was 0,26826 in dogs.

Conclusion Mean values measured by Tono-Pen Vet where in the correct range for dogs, but we conclude in comparison with the data of other studies, that values measured with a Tono-Pen Vet could be 5-6 mmHg higher than measured by another tonometers, like Perkins or TonoVet.

The advantages of using the Tono-Pen Vet tonometer include the ease of taking the IOP measurement reading, ease of visualization of measurement readings, ease of disinfecting and long-term battery life. The disadvantages include frequent calibration, reduced accuracy and underestimation of true IOP compared to manometry and cost of the Tono-Pen Vet is higher, than for example Schiotz Tonometer or Perkins.

Key words: tonometry, intraocular pressure (IOP), Tono-Pen Vet
\end{abstract}

Citation:

Wrześniewska, K., Winiarczyk, D., Madany, J. (2016). The advantages of using the Tono-Pen Vet tonometer in the measurement of IOP in veterinary practice. Scientific Messenger LNUVMBT named after S.Z. Gzhytskyj, 18, 2(66), 234-236.

\section{Introduction}

Wczesne wykrycie zmian w wysokości ciśnienia wewnątrzgałkowego (IOP) stanowi istotny element diagnostyki i efektywnego leczenia chorób narządu wzroku takich jak zapalenie błony naczyniowej, jaskra, nadciśnienie oczne, nowotwory wewnątrzgałkowe czy urazy pooperacyjne. Przypuszcza się też, że może mieć wartość diagnostyczną także w chorobach układowych, np. serca i nerek (Kański, 2005; Wojciechowska and Bryła, 2011).

Objętość cieczy wodnistej w gałce ocznej jest uważana za główny czynnik, decydujący o wielkości ciśnienia śródocznego (IOP - intraocular pressure). Z badań wykonanych na dużych grupach zwierząt wynika, że prawidłowa wartość ciśnienia IOP u psów i kotów wynosi od 10 do $20 \mathrm{~mm} \mathrm{Hg}$. Jednak na wartości IOP duży wpływ wywierają: rasa i wielkość zwierzęcia, pora dnia, metoda pomiaru, a także czynniki egzo- i endogenne, w tym środki uspokajające i trankwilizatory oraz anestetyki, a również ucisk dookoła szyi lub okolicy oczodołu np. przy nieprawidłowym poskromieniu psa i przygotowaniu go do badania. Dlatego przyjmuje się, że podstawą do interpretacji wyników powinno być porównanie wysokości ciśnienia w obu gałkach ocznych, gdy różnica nie przekracza 20\% (Maggs, 2009).

Pomiar ciśnienia wewnątrzgałkowego może być wykonywany za pomocą manometrii oraz szacunkowo przy pomocy tonometrów.

Manometria jest procedurą inwazyjną używaną wyłącznie w eksperymentalnych pomiarach IOP oraz w pomiarach służących weryfikowaniu dokładności pomiarów uzyskiwanych za pomocą tonometrów (Andrade et al., 2012).

Tonometria jest metodą pomiaru IOP wykonywaną za pomocą specjalnych przyrządów, zwanych tonometrami, które wykorzystują różne techniki do oceny oporu jaki stawia ściana gałki ocznej pod wpływem wywieranego nacisku. Obecnie badanie tonometryczne może być przeprowadzone trzema metodami. Każda $\mathrm{z}$ nich opiera 
się na innej zasadzie. Stosuje się tonometry impresyjne (wgłębiające), przykładem takiego tonometru jest tonometr Schiotza, tonometry aplanacyjne (zwane inaczej spłaszczającymi), m.in. Tono-Pen, Tono-Pen Vet czy Air Puff, czy tonometry rebundacyjne (impaktowe) TonoVet, i-Care (Madany et al., 1995; Schottenstein, 1996; Wojciechowska and Bryła, 2011).

Celem pracy jest porównanie wyników ciśnienia wewnątrzgałkowego uzyskanych metodą tonometrii aplanacyjnej z wykorzystaniem tonometru Tono-Pen Vet w $\mathrm{z}$ danymi literatury oraz wskazanie zalet $\mathrm{i}$ wad tej metody w praktyce lekarsko-weterynaryjnej.

\section{Material and methods}

W ostatniej dekadzie powstały urządzenia elektroniczne, których przedstawicielem jest Tono-Pen. Jak wskazuje nazwa, urządzenie to przypomina długopis. Jest często wybierane przez lekarzy weterynarii ze względu na nieskomplikowaną obsługę i łatwość przenoszenia. Tono-Pen działa poprzez mierzenie siły potrzebnej do spłaszczenia rogówki i za pomocą mikroprocesora analizuje wielkość użytej siły oraz czas jej działania. Ponieważ siła ta równa jest ciśnieniu wywieranemu od wewnątrz na rogówkę, znając jej wartość oblicza się ciśnienie wewnątrzgałkowe. Wynik pomiaru IOP wyświetla się na ekranie ciekłokrystalicznym i podawany jest w mm Hg. Niektóre modele Tono-Penu wymagają codziennej kalibracji urządzenia (Madany et al., 1995; Kański, 2005; Maggs, 2009; Wojciechowska and Bryła, 2011).

Badanie przeprowadzono u pacjentów Katedry i Kliniki Chorób Wewnętrznych Zwierząt Uniwersytetu Przyrodniczego w Lublinie, uzyskując zgodę właścicieli. Badano grupę 41 zdrowych klinicznie psów, różnych ras i mieszańców, obuocznie. Wśród nich było 18 samców i 23 samice, w wieku od 4 miesięcy do 13 lat.

Ciśnienie wewnątrzgałkowe było mierzone tonometrem Tono-Pen Vet po wcześniejszym podaniu do obu worków spojówkowych $1-2$ kropli $0,5 \%$ Alcaine. Wszystkie pomiary były wykonywane przez tego samego lekarza zgodnie z instrukcją obsługi tonometru. Pacjenci byli lekko podtrzymywani przez asystenta tak aby nie powodować ucisku na okolicę głowy i szyi.

\section{Results}

W badanej grupie psów średnie wartości IOP mierzone przyrządem Tono-Pen Vet wynosiły 18,5 \pm 3,7 mmHg (zakres 11,5 - 24,5 mmHg). Wyniki przedstawiono $\mathrm{w}$ tabeli $\mathrm{nr} 1$.

Tabela 1 .

Uzyskane wartości ciśnienia wewnątrzgałkowego (IOP) w mm Hg u zdrowych klinicznie psów $(\mathrm{n}=41)$

\begin{tabular}{|l|l|l|l|}
\hline & $\begin{array}{l}\text { Tono-Pen Vet } \\
\text { OL }\end{array}$ & $\begin{array}{l}\text { Tono-Pen Vet } \\
\text { OP }\end{array}$ & $\begin{array}{l}\text { Tono-Pen Vet } \\
\text { średnia }\end{array}$ \\
\hline Średnia \pm SD & $17,7 \pm 4,4$ & $19,2 \pm 4,8$ & $18,5 \pm 3,7$ \\
\hline Minimum & 11 & 11 & 11,5 \\
\hline Maximum & 27 & 33 & 24,5 \\
\hline
\end{tabular}

Współczynnik korelacji $\left(\mathrm{r}^{2}\right)$ pomiędzy wartościami IOP mierzonymi w OL i OP Tono-Pen Vet wynosił 0,268264, co świadczy o braku zależności między uzyskanymi pomiarami. (Wykres 1)

Wykres 1. Porównanie wartości ciśnienia wewnątrzgałkowego (IOP) mierzonego u zdrowych klinicznie psów $(n=41)$. Wykres rozrzutu przedstawia wartości wyliczone z użyciem współczynnika korelacji metodą Spearmana dla $\mathrm{P} \leq 0,05$.

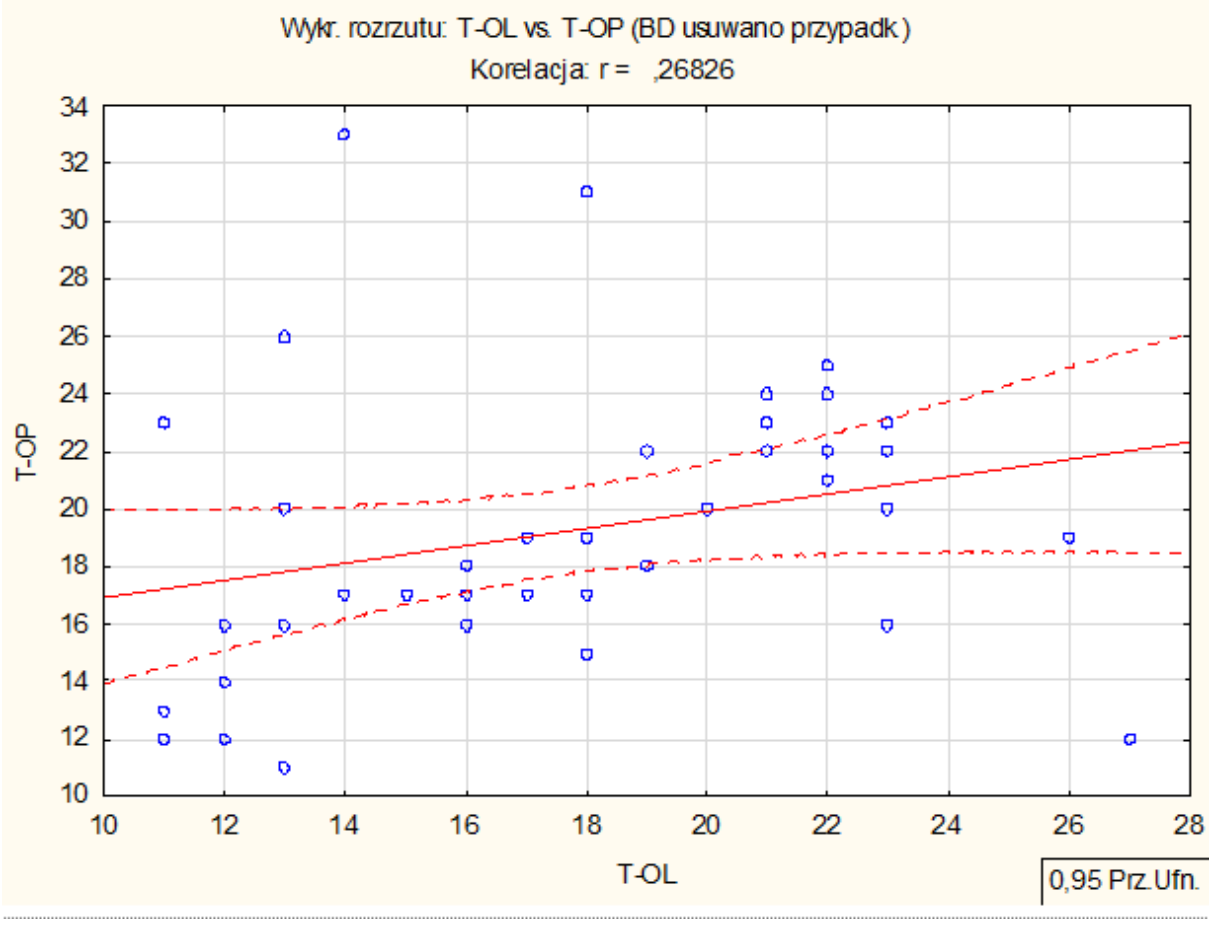




\section{Discussion}

W medycynie weterynaryjnej najpopularniejszymi przyrządami do pomiaru ciśnienia wewnątrzgałkowego są ręczne tonometry aplanacyjne typu Tono-Pen, Tono-Pen Vet oraz tonometry rebundacyjne typu Tono-Vet. (Knollinger et al., 2005; Leiva et al., 2006; von Spiessen et al., 2015).

W przeprowadzonych badaniach własnych uzyskane średnie wartości IOP u psów były zbliżone do tych odnotowanych przez Gellata i MacKay'a (1998), mierzonych za pomocą Tono-Pen XL (19,2 \pm 5,9 mmHg). (Gelatt and MacKay, 1998).

Z kolei badania przeprowadzone na królikach (Lim et al. 2005 i Kalesnykas et al. 2007) porównujące efektywność i dokładność znanych typów tonometrów:

Tono-pen XL, Perkins, OBF pneumatonometer, czy TonoVet mogą sugerować, iż Tono-Pen XL może wykazywać mniejszą dokładność niż pozostałe, dlatego ważne jest badanie przydatności klinicznej jego weterynaryjnego odpowiednika Tono-Pen Vet. (Lim et al., 2005; Kalesnykas and Uusitalo, 2007).

Badanie przeprowadzone u ludzi, porównujące TonoPen XL i tonometr Goldmanna sugeruje niższą dokładność pomiaru Tono-Pen XL przy wyższych wartościach IOP. (Iester et al., 2001).

Do podobnych wniosków doszedł Andrade et al. (2012), który w badaniu przeprowadzonym na psach i kotach porównującym pomiary metodą Tono-Pen XL i tonometrem Perkinsa nie zaobserwował ważnych statystycznie różnic pomiędzy średnimi pomiarami IOP, a jedynie różnicę między minimalnymi i szczególnie maksymalnymi wartościami, które były średnio o 5-6 mmHg wyższe przy pomiarach Tono-Pen XL niż mierzonych tonometrem Perkinsa. (Andrade et al., 2012).

Porównując wyniki pomiaru ciśnienia w obu gałkach ocznych pacjenta oraz wykres rozrzutu przedstawiający wartości wyliczone z użyciem współczynnika korelacji metodą Spearmana dla $\mathrm{P} \leq 0,05$, można wnioskować, iż różnica ciśnienia $\mathrm{w}$ obu gałkach ocznych u części pacjentów przekraczała $20 \%$, co skłania do użycia metod porównawczych i przeprowadzenia doświadczenia na większej grupie psów.

Z obserwacji praktycznych wynika, iż stosowanie Tono-Pen Vet ma sporo zalet. Natychmiastowo uzyskuje się odczyt wartości IOP. Dzięki możliwości szybkiego wykonania badania przyrząd jest łatwy w użyciu u zwierząt młodych i o żywym temperamencie, w porównaniu np. do tonometru Schiotza. Jest prosty $w$ obsłudze, latwy $w$ przenoszeniu i przechowywaniu, baterię cechuje długa żywotność. Wymienione cechy mają wpływ na stale rosnącą popularność tego typu sprzętu. Dezynfekcja urządzenia polega na każdorazowej wymianie końcówek («tip-cover») po dokonaniu pomiaru.

Do wad urządzenia można zaliczyć konieczność częstej kalibracji oraz wysoki koszt zakupu, ok. 10krotnie wyższy niż w przypadku zakupu tonometru Schiotza.

Z uwagi na fakt, iż schorzenia gałki ocznej przebiegające ze zmianą ciśnienia śródgałkowego znacznie pogarszają komfort życia zwierząt, istotne jest ich wczesne wykrywanie i stosowanie proporcjonalnej terapii. Dlatego ważne jest, by tonometria stała się badaniem rutynowo wykorzystywanym w diagnostyce chorób oczu, a także badaniem stosowanym u starszych zwierząt (Wojciechowska and Bryła,2011).

\section{References}

Andrade, S., Cremonezi, T., Aparecida, C., Zachi, M., Ferreira Lonchiati, C., Dalarrosa Amatuzzi, J., Sakamoto, K., de Arruda Mello, P. (2009). Evaluation of the Perkins handheld applanation tonometer in the measurement of intraocular pressure in dogs and cats. Veterinary Ophthalmology. 12, 277-284.

Andrade, S.F., Palozzi, R.J., Giuffrida, R., de Campos, R.J., de Campos Santos, G., Fukui, R.M. (2012). Comparison of intraocular pressure measurements between the Tono-Pen XL and Perkins applanation tonometers in dogs and cats. Veterinary Ophthalmology. 15, 14-20.

Gelatt, K.N., MacKay, E.O. (1998). Distribution on intraocular pressure in dogs. Veterinary Ophthalmology. 1, 109-114.

Iester, M., Mermoud, A., Achache, F., Roy, S. (2001). New Tono-Pen XL: comparison with the Goldmann tonometer. Eye. 15, 52-58.

Kalesnykas, G., Uusitalo, H. (2007). Comparison of simultaneous readings of intraocular pressure in rabbits using Perkins handheld, Tono-Pen XL, and TonoVet tonometers. Graefe's Archives of Clinical Experimental Ophthalmology,245, 761-762.

Kański, J.J. (2005). Okulistyka Kliniczna. Górnicki Wydawnictwo Medyczne, Wrocław, 196-198.

Knollinger, A.M., La Croix, N.C., Barrett, P.M., Miller, P.E. (2005). Evaluation of a rebound tonometer for measuring intraocular pressure in dogs and horses. J. Am Vet Med Assoc. 227, 244-248.

Leiva, M., Naranjo, C., Peña, M.T. (2006). Comparison of the rebound tonometer (Icare) to the applanation tonometer (Tono-Pen XL) in normotensive dogs. Veterinary Ophthalmology. 9, 17-21.

Lim, K.S., Wickremasinghe, S.S., Cordeiro, M.F., Bunce, C., Khaw, P.T. (2005). Accuracy of intraocular pressure measurements in New Zealand white rabbits. IOVS. 46, 2419-2423.

Madany, J., Clerc, B., Pomorski, Z. (1995). Tonometria mierzenie napięcia gałki ocznej. MW. 4, 37-38.

Maggs, D.J. (2009). Podstawowe techniki diagnostyczne. In: Okulistyka weterynaryjna Slattera. Elsevier Urban \& Partner, Wrocław, 104-107.

Schottenstein, E.M. (1996). Intraocular pressure and tonometry. In: Ritch R, Shields MB, Krupin T (ed) The Glaucomas - Basic Sciences, $2^{\text {nd }}$ ed. St. Louis, Mosby, 407-428.

von Spiessen, L., Karck, J., Rohn, K., Meyer-Lindenberg, A. (2015). Clinical comparison of the TonoVet rebound tonometer and the Tono-Pen Vet applanation tonometer in dogs and cats with ocular disease: glaucoma or corneal pathology. Veterinary Ophthalmology. 18, 20-27.

Wojciechowska, M., Bryła, P.K. (2011). Tonometria pomiar ciśnienia śródocznego. PJVO. 2, 1-8.

Стаття надійшла до редакиії 28.09.2016 